\title{
To identify and analyze the marketing channels for hybrid cotton seeds in North Karnataka
}

\author{
Srividyarani S. Sajjan and N. M. Kerur
}

Received : 30.01.2018; Revised : 07.03.2018; Accepted : 21.03.2018

\begin{abstract}
The cotton seed industry has emerged as an important component in the seed market basically due to its ability for development of hybrids and diversity of production. The study was taken in Haveri and Dharwad districts of North Karnataka. In the study area two marketing channels were identified through which hybrid cotton seeds in the study area were marketed from the producers to the ultimate consumers. In Dharwad and Haveri channel I is having the highest marketing efficiency (2.28\%) and (2.24\%) compared to channel II. The poor efficiency was noticed in Channel II where the total marketing cost was the highest in this channel, this is because of involvement of intermediaries. So the results reveled that channel I is more popular in the study area. In both districts Channel II is preferred more by the dealers. The highest percentage of margin obtained by the dealer varied from 12.72 per cent in kanaka and lowest per cent of margin 8.70 is obtained in cash brand.
\end{abstract}

KEY WORDS : Marketing efficiency, Marketing margin, Marketing channels, Hybrid cotton seed

How to cite this paper : Sajjan, Srividyarani S. and Kerur, N.M. (2018). To identify and analyze the marketing channels for hybrid cotton seeds in North Karnataka. Internat. J. Com. \& Bus. Manage, 11(1) : 44-48, DOI: 10.15740/HAS/IJCBM/11.1/44-48. 